\title{
The molecular mechanism of treating osteoarthritis with dipsacus saponins by inhibiting chondrocyte apoptosis
}

\author{
XIAN-RANG LI ${ }^{1,2}$, JIAN LI ${ }^{2}$, QIANG REN ${ }^{2}$ and SHUI SUN ${ }^{1}$ \\ ${ }^{1}$ Department of Joint Surgery, Shandong Provincial Hospital Affiliated to Shandong University, Jinan, Shandong 250012; \\ ${ }^{2}$ Department of Joint Surgery, Affiliated Hospital of Binzhou Medical University, Binzhou, Shandong 256603, P.R. China
}

Received June 17, 2016; Accepted April 21, 2017

DOI: $10.3892 /$ etm.2017.5072

\begin{abstract}
The present study aimed to determine the molecular mechanism of treating osteoarthritis with dipsacus saponins by inhibiting the apoptosis of chondrocytes. A total of $30 \mathrm{New}$ Zealand rabbits were randomly divided into 2 groups: A control group and a model group. The osteoarthritis model was established using the HULTH method. The success of the model establishment was determined by pathological morphology and measurement of inflammatory cytokine levels. Chondrocytes were isolated and divided into 4 groups treated with varying concentrations of dipsacus saponins: 0 , 25, 50 and $100 \mu \mathrm{g} / \mathrm{l}$ dipsacus saponins. Cell cycle distribution was analyzed using flow cytometry. Changes in cyclin D1, cyclin-dependent kinase 4 (CDK4) and p21 expression were detected by western blotting and changes in the levels of Bcl-2, Bax, caspase-3 and caspase- 9 mRNA were detected using reverse transcription-quantitative polymerase chain reaction. The osteoarthritis model was established successfully, indicated by a significant increase in the levels of IL-1 $\beta$, IL- 6 and TNF- $\alpha$ in the model group $(\mathrm{P}<0.05)$ compared with the control group. The viability of the chondrocytes increased following treatment with dipsacus saponins in a concentration-dependent manner. The number of chondrocytes in the G0/G1 phase decreased in the 50 and $100 \mu \mathrm{g} / 1$ groups while the number of chondrocytes in the $\mathrm{G} 2 / \mathrm{M}$ phase increased in the 50 and $100 \mu \mathrm{g} / 1$ groups. Levels of cyclin D1 and CDK4 expression increased following treatment with dipsacus saponins. Levels of Bax, caspase- 3 and caspase- 9 expression decreased while Bcl-2 levels increased following treatment with dipsacus saponins. The viability of chondrocytes increased following treatment with dipsacus saponins in a concentration-dependent manner. Thus, dipsacus saponins inhibited the apoptosis of
\end{abstract}

Correspondence to: Dr Shui Sun, Department of Joint Surgery, Shandong Provincial Hospital Affiliated to Shandong University, 324 Jing Wu Road, Jinan, Shandong 250012, P.R. China

E-mail: sunshuis@sina.com

Key words: dipsacus saponins, osteoarthritis, chondrocytes, apoptosis, inflammatory cytokines chondrocytes by up-regulating $\mathrm{Bcl}-2$ and down-regulating caspase-9, caspase-3 and Bax expression.

\section{Introduction}

Osteoarthritis (OA) is a chronic joint disease characterized by articular cartilage degeneration and secondary bone hyperplasia. Its early symptoms are joint pain, swelling and deformity, which may affect patient quality of life as the disease progresses $(1,2)$. The overall prevalence of OA is $10-12 \%$. OA is more common in the elderly, $\sim 60 \%$ of people with X-ray osteoarthritis. Load-bearing and more active joints are more prone to developing OA, especially the knee joint (3-7). The most basic pathological change of knee osteoarthritis is the degeneration and degeneration of articular cartilage (6). Changes in the morphology and metabolism of chondrocytes and in the biochemical and structural composition of the matrix are considered to be important induction factors of OA (7). The most common method to diagnose OA patients is radiographic examination using the Kellgren-Lawrence grading system and magnetic resonance imaging $(8,9)$. Drugs, including non-steroidal anti-inflammatory analgesics and steroids, are primarily used to control the acute pain, swelling and other symptoms experienced by patients with OA. However, there are currently no effective treatments or drugs able to prevent or reverse disease progression $(10,11)$.

The Chinese teasel root is able to nourish the liver and kidney, strengthen the bones and stimulates tocolysis. Saponins are the primary effective components of the teasel root and 18 types of triterpenoid saponins have been isolated to date. It has been demonstrated that the Chinese teasel root promotes the proliferation and differentiation of osteoblasts, and is able to regulate immune function, indicating that it may be used to treat arthritis (12). A kind of saponin in the medicinal herb Dipsacus asper wall has been used as an antiosteoporosis drug (13). However, its therapeutic mechanism of action remains unclear and further studies are required to screen and separate active components. It is important to determine the pharmacological effect and mechanism of action of Chinese teasel root to identify the active components. Thus the present study assessed the molecular mechanism of treating OA with Dipsacus saponins extracted from the Chinese teasel root by inhibiting the apoptosis of chondrocytes. 


\section{Materials and methods}

Experimental animals. A total of 30 specific-pathogen-free New Zealand female rabbits with a mean weight of $3.0 \pm 0.5 \mathrm{~kg}$ (age, 6 months) were obtained from Vital River Laboratories, Co., Ltd. (Beijing, China). They were fed at $18-25^{\circ} \mathrm{C}$, humidity $40-50 \%$, in a natural light cycle, with free access to food and water. These rabbits underwent pre-feeding for 7 days with free access to food and water to adapt to their environment. Ventilation of the feeding room was good and rabbits were exposed to natural lighting. The rabbits were randomly divided into a control group $(n=10)$ and model group $(n=20)$. The OA model was established using Hulth's modeling method (14). Animals were anesthetized with $30 \mathrm{mg} / \mathrm{kg}$ intravenous injection of 3\% sodium pentobarbital (Sigma-Aldrich; Merck KGaA, Darmstadt, Germany). The rabbits were in the supine position and a longitudinal incision in the inner side of right hind knee joint was performed. The joint cavity was exposed, the meniscus of the right hind leg was resected completely, the tibial collateral ligament and anterior and posterior ligaments were cut off and the wound was sutured layer by layer and bound using a sterile dressing. Model rabbits were treated with intramuscular injection of penicillin sodium 20,000,000 U/day for 3 days, whereas the control group received no treatment. The success of the model establishment was determined by pathological morphology (cystic degeneration and osteophyte formation) and measurement of the levels of related inflammatory cytokines [increased interleukin (IL)-1 $\beta$, IL- 6 and tumor necrosis factor (TNF)- $\alpha$ ]. Housing conditions and procedures involving experimental animals were in accordance with the Guide for the Care and Use of Laboratory Animals (15). All experimental procedures were approved by the Care of Experimental Animals Committee of Shandong Provincial Hospital (Jinan, China).

Detection of IL-1 $\beta, I L-6$ and TNF- $\alpha$ using ELISA. Synovial fluid was obtained by intra-articular injection of saline at 6 weeks after surgery. Levels of IL-1 $\beta$, IL- 6 and TNF- $\alpha$ in the synovial fluid were detected using ELISA kits (cat. nos. ml112819, ml102828 and ml002859; Shanghai Meilian Biological Technology Co., Ltd.), according to the manufacturer's instructions. Optical density values at $450 \mathrm{~nm}$ were determined by an ELISA detector (MR-96A, Mindray, Guangzhou, China).

Isolation of chondrocytes and treatment with dipsacus saponins. Rabbits were anesthetized and sacrificed at 6 weeks after surgery with artery air-embolism $(\sim 5 \mathrm{ml} / \mathrm{kg})$ and rabbit femurs were isolated under aseptic condition. Soft tissue and the periosteum were removed, the femoral metaphysic was cut off and the fracture end was washed with phosphate-buffered saline 3 times. The femoral metaphysic was cut into bone pieces and cultured with $2 \mathrm{~g} / \mathrm{l}$ collagenase II (Gibco; Thermo Fisher Scientific, Inc.) at $37^{\circ} \mathrm{C}$ for $1.5 \mathrm{~h}$. The digestive liquid was discarded and Dulbecco's Modified Eagle's medium (DMEM; Gibco; Thermo Fisher Scientific, Inc.) was added and cultured at $37^{\circ} \mathrm{C}$ with $5 \% \mathrm{CO}_{2}$ for 7 days. A cell viability curve was constructed using the MTT method. Purple formazan was dissolved in dimethyl sulfoxide. Absorbance was measured using a spectrophotometer at $570 \mathrm{~nm}$.
Cells were treated with dipsacus saponins (cat. no. 33289-85-9; Shanghai Yuanye Biological Technology Co., Ltd.) following three generations $\left(37^{\circ} \mathrm{C}, 5 \% \mathrm{CO}_{2}\right)$ and were divided into $0,25,50$ and $100 \mu \mathrm{g} / 1$ dipsacus saponin groups. Cell cycles were measured using flow cytometry following $72 \mathrm{~h}$ culture at $37^{\circ} \mathrm{C}$ in DMEM, using the Cell Cycle and Apoptosis Analysis kit (cat. no. C1052; Beyotime Institute of Biotechnology, Shanghai, China) and a flow cytometer. Results were analyzed using BD FACSComp software (v5.1, BD Biosciences, Franklin Lakes, NJ, USA). Chondrocytes in the OA model group were treated with sodium nitroprusside (SNP; Sigma-Aldrich; Merck KGaA) to induce apoptosis. Chondrocytes were cultured with DMEM containing $1 \mathrm{mmol} / \mathrm{l}$ SNP and $10 \%$ fetal bovine serum for $24 \mathrm{~h}$ and then treated with dipsacus saponins for $24 \mathrm{~h}$.

$R N A$ extraction and reverse transcription-quantitative polymerase chain reaction ( $R T-q P C R)$. Harvested cells were washed with RNase free PBS. Total RNA was extracted using an RNeasy Mini kit (cat. no. 74104; Qiagen China Co., Ltd., Shanghai, China) according to the manufacturer's protocol. RNA concentration and purity were detected using a Qubit Fluorometer (Thermo Fisher Scientific, Inc.). A total of $1 \mu \mathrm{g}$ RNA was subjected to reverse transcription using a reverse transcription kit (Promega Corporation, Madison, WI, USA). qPCR was performed using a SYBR Green PCR Master mix (Qiagen, Inc., Valencia, CA, USA) and the primers used are presented in Table I. The quantification method used was the $2^{-\Delta \Delta C q}$ method as described previously (16). GAPDH gene was used as an internal control. The thermocycling conditions were as follows: Pre-degeneration at $95^{\circ} \mathrm{C}$ for $10 \mathrm{~min}$, followed by 40 cycles of degeneration at $95^{\circ} \mathrm{C}$ for $10 \mathrm{sec}$, annealing at $56^{\circ} \mathrm{C}$ for $20 \mathrm{sec}$ and extension at $72^{\circ} \mathrm{C}$ for $33 \mathrm{sec}$.

Western blotting. Cells were lysed with radioimmunoprecipitation assay lysis buffer (BioVision, Inc., Milpitas, CA, USA). Total proteins were extracted and and protein concentration was determined using BCA. Proteins (50 $\mu \mathrm{g}$ per lane) were separated using $12 \%$ SDS-PAGE. Proteins were then electrotransferred to a PVDF membrane. The PVDF membrane was rinsed with TBS for 10-15 min, placed in TBS/T blocking buffer containing $5 \%(\mathrm{w} / \mathrm{v})$ skimmed milk powder and shaken at room temperature for $1 \mathrm{~h}$. It was incubated at room temperature for $2 \mathrm{~h}$ following the addition of an appropriate dilution of primary antibody (diluted with TBST containing $1 \%$ (w/v) skimmed milk powder). Primary antibodies were as follows: $\beta$-actin (dilution, 1:1,000; cat. no. 143128; United States Biological, Salem, MA, USA), CDK4 (1:5,000; cat. no. AHZ0202; Thermo Fisher Scientific, Inc.), p21 (1:5,000; cat. no. 701151; Thermo Fisher Scientific, Inc.) and Cyclin D1 (1:5,000; cat. no. 710428; Thermo Fisher Scientific, Inc.). The membrane was then rinsed with TBST three times (5-10 $\mathrm{min} / \mathrm{wash})$ and then incubated at room temperature for $1 \mathrm{~h}$ with horseradish peroxidase-labeled secondary antibody (1:10,000; cat. no. 32260; Thermo Fisher Scientific, Inc.) diluted with TBST containing $0.05 \%$ (w/v) skimmed milk powder. The membrane was then rinsed three times with TBST (5-10 min/wash). Protein bands were detected using an enhanced chemiluminescence kit (cat. no. K820-500; 
Table I. Primers used in reverse transcription-quantitative polymerase chain reaction.

\begin{tabular}{llll}
\hline Gene & GenBank accession no. & \multicolumn{1}{c}{ Primer (5'-3') } & \multicolumn{1}{c}{ Length (bps) } \\
\hline Bcl-2 & DQ_529234.1 & For: GAGCCATCTCAGTGTGTGGAG & 21 \\
& & Rev: GCCAGCATTGCCATAAAAGAGTC & 23 \\
Bax & XM_002723696.2 & For: CCCGAGAGGTCTTTTCCGAG & 21 \\
Caspase-3 & NM_001082117.1 & Rev: CCAGCCCATGATGGTTCTGAT & 21 \\
Caspase-9 & & For: CATGGAAGCGAATCAATGGACT & 22 \\
EAPDH & Rev: CTGTACCAGACCGAGATGTCA & 21 \\
& NM_014364 & For: CTTCGTTTCTGCGAACTAACAGG & 23 \\
& & Rev: GCACCACTGGGGTAAGGTTT & 21 \\
\end{tabular}

For, forward; Rev, reverse.

Table II. IL-1 $\beta$, IL-6, TNF- $\alpha$ levels in the synovial fluid as detected by ELISA.

\begin{tabular}{lccc}
\hline Group & IL-1 $\beta$ & IL-6 & TNF- $\alpha$ \\
\hline Control $(\mathrm{pg} / \mathrm{ml})$ & $12.11 \pm 1.77$ & $16.54 \pm 1.97$ & $5.38 \pm 1.15$ \\
Model $(\mathrm{pg} / \mathrm{ml})$ & $36.56 \pm 4.57^{\mathrm{a}}$ & $36.96 \pm 3.08^{\mathrm{b}}$ & $29.61 \pm 3.62^{\mathrm{a}}$
\end{tabular}

All results are presented as the mean \pm standard deviation. ${ }^{\mathrm{a}} \mathrm{P}<0.01$; ${ }^{\mathrm{b}} \mathrm{P}<0.05$ vs. control. IL, interleukin; TNF, tumor necrosis factor.

BioVision, Inc.) and quantified as the ratio to $\beta$-actin. Quantification was performed using ImageJ software (v1.37; National Institutes of Health, Bethesda, MD, USA).

Statistical analysis. All results are presented as the mean \pm standard deviation and analyzed using SPSS 20.0 software (IBM Corp., Armonk, NY, USA). One-way analysis of variance and Student's t test were used to evaluate the differences between groups. $\mathrm{P}<0.05$ was considered to indicate a statistically significant difference.

\section{Results}

OA model. Rabbits in control group were normal and able to move their joints freely. In model rats, restricted joint movement was observed 6 weeks after the operation. The surface and edges of joints from rabbits in the control group were smooth with a clear and bright color and the synovial joint fluid was clear. By contrast, the joint surface of rabbits in the model group was rough with irregular edges and tiny cracks and the joint synovial fluid was turbid (data not shown).

The results of ELISA measuring IL- $1 \beta$, IL- 6 and TNF- $\alpha$ levels in the synovial fluid in all rabbits are presented in Table II. The levels of IL-1 $\beta$, IL- 6 and TNF- $\alpha$ in the synovial fluid of rabbits in the model group were significantly higher than those of control rabbits $(\mathrm{P}<0.05)$, indicating that the $\mathrm{OA}$ model was successfully established.

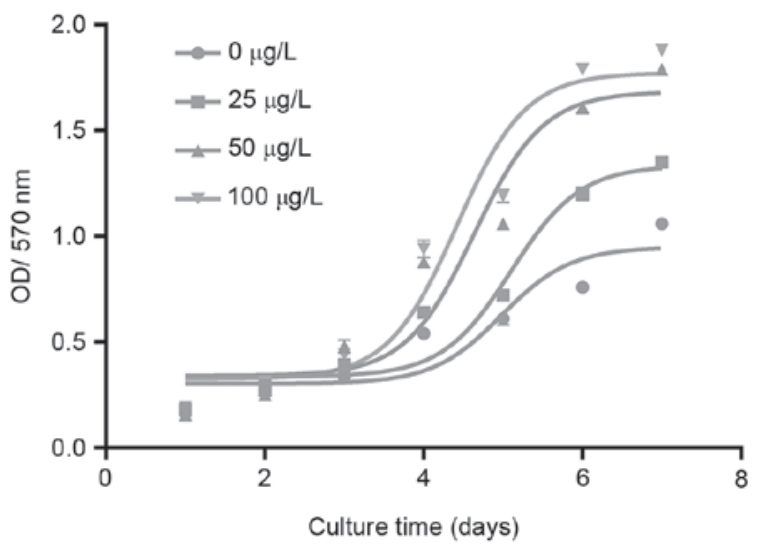

Figure 1. Viability curve of chondrocytes. The viability of chondrocytes increased as the concentration of dipsacus saponins increased. OD, optical density.

Dipsacus saponins promote the viability of chondrocytes. The cell viability curves of the different groups of chondrocytes (treated with 0, 25, 50 and $100 \mu \mathrm{g} / \mathrm{l}$ dipsacus saponins) are presented (Fig. 1). This demonstrates that the viability of chondrocytes increased following treatment with dipsacus saponins in a concentration-dependent manner.

The results from flow cytometry demonstrated that the number of chondrocytes in the G0/G1 phase decreased in the groups treated with 50 and $100 \mu \mathrm{g} / 1$ dipsacus saponins, whereas the number of chondrocytes in the $\mathrm{G} 2 / \mathrm{M}$ phase increased in these groups (Fig. 2).

The results from western blotting are presented in Fig. 3. Levels of Cyclin Dl and cyclin-dependent kinase 4 (CDK4) expression increased in groups treated with 50 and $100 \mu \mathrm{g} / \mathrm{l}$ dipsacus saponins and this increase occurred in concentration-dependent manner. By contrast, levels of p21 expression decreased in the groups treated with 50 and $100 \mu \mathrm{g} / 1$ dipsacus saponins and this decrease occurred in a concentration-dependent manner.

Dipsacus saponins inhibit the apoptosis of chondrocytes. Exogenous SNP was added to cells to induce apoptosis. Cells 
A
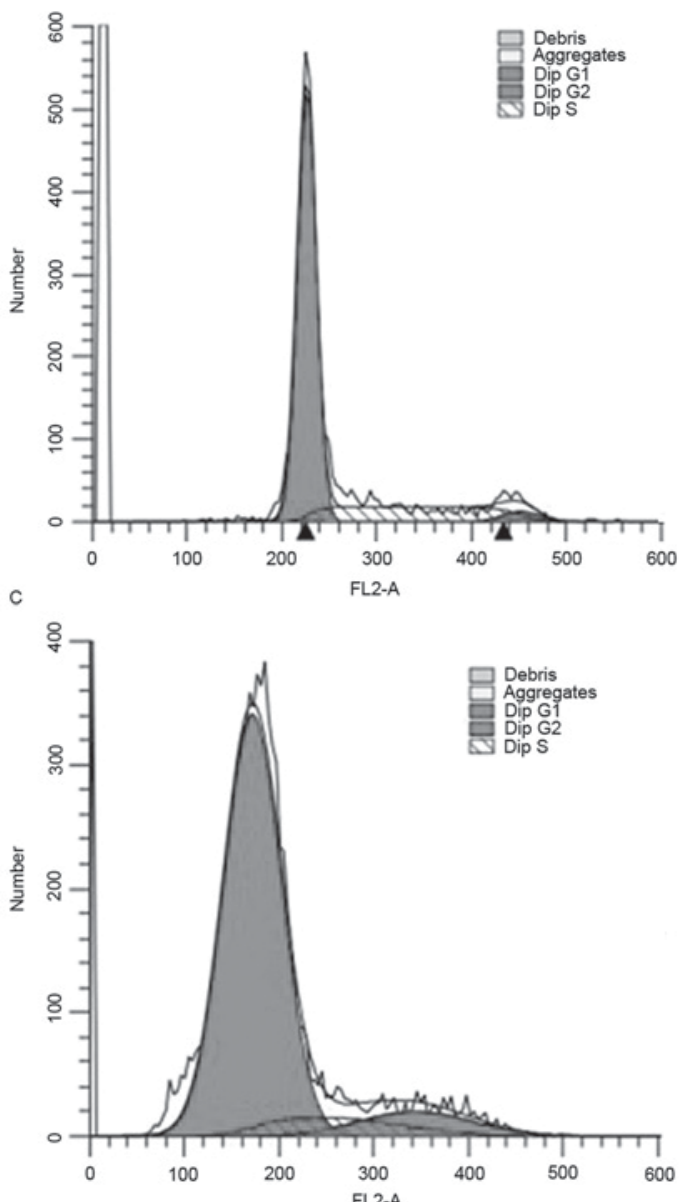
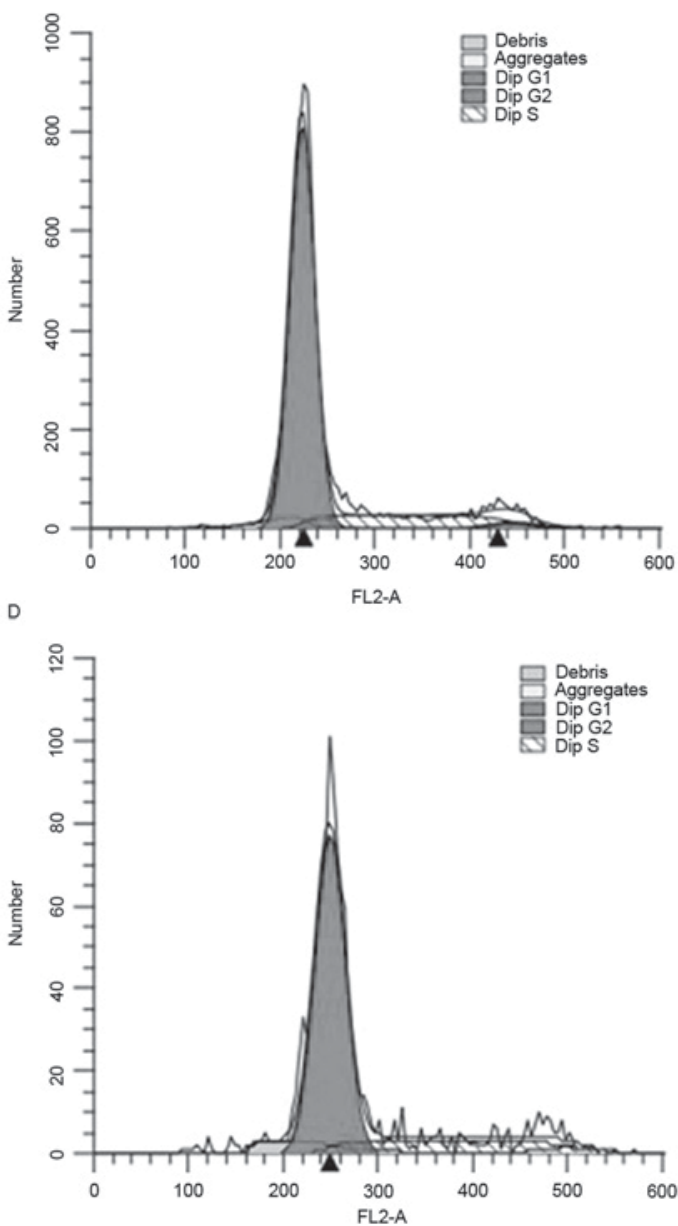

Figure 2. Flow cytometry results of cell cycles. Cells were treated with (A) 0 , (B) 25 , (C) 50 and (D) $100 \mu \mathrm{g} / 1$ dipsacus saponins.

$B$
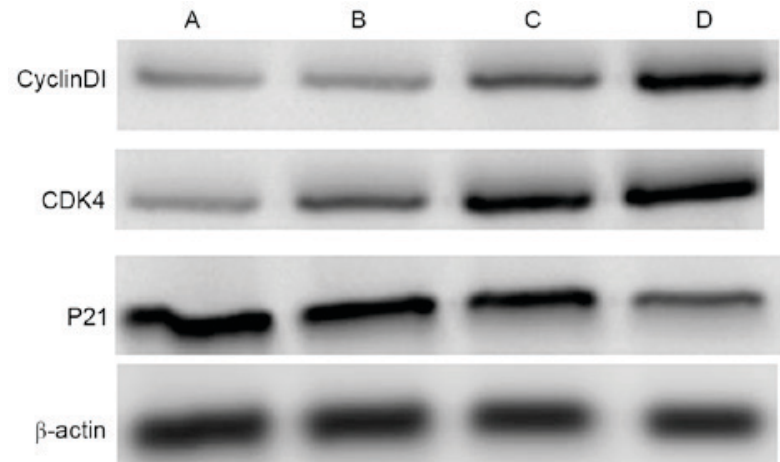

Figure 3. Expression of Cyclin D1, CDK4 and p21 in the different groups. Cells were treated with (A) 0, (B) 25, (C) 50 and (D) $100 \mu \mathrm{g} / 1$ dipsacus saponins. Levels of Cyclin Dl and CDK4 expression increased in groups treated with 50 and $100 \mu \mathrm{g} / 1$ dipsacus saponins. By contrast, levels of p21 expression decreased in the groups treated with 50 and $100 \mu \mathrm{g} / 1$ dipsacus saponins. CDK4, cyclin-dependent kinase 4.

were then treated with $0,25,50$ or $100 \mu \mathrm{g} / 1$ dipsacus saponins. Levels of Bcl-2, Bax, caspase-3 and caspase-9 mRNA were measured by RT-qPCR. The results demonstrated that levels of Bax, caspase-3 and caspase- 9 mRNA decreased following treatment with dipsacus saponins in a concentration-dependent manner. The decreases in levels of Bax, caspase- 3 and caspase- 9 mRNA were significant following treatment with
$100 \mu \mathrm{g} / 1$ dipsacus saponins $(\mathrm{P}<0.01)$. By contrast, levels of Bcl-2 mRNA significantly increased in chondrocytes treated with $100 \mu \mathrm{g} / 1$ dipsacus saponins ( $\mathrm{P}<0.05$; Fig. 4).

\section{Discussion}

Chondrocytes help maintain joint function and serve an important role in the development of OA (17). The pathological changes that occur in OA primarily manifest as cartilage lesions, which lead to degenerative changes occurring in the cartilage cells and matrix (18). The animal model of OA used in the current study facilitated the study of OA pathogenesis. The current study evaluated dipsacus saponins as a potential therapeutic drug to treat OA and determined its effect on chondrocytes.

The shape of chondrocytes is irregular at the early stages of culture (19). The current study determined that chondrocyte viability increased following treatment with dipsacus saponins in a concentration-dependent manner, suggesting that dipsacus saponins serve a role in promoting cell viability. Alterations in the cell cycle affect the lifespan of cells. Promoting the proliferation of chondrocytes is an efficient treatment to delay the progression of cartilage degradation (20). It was determined that the proportion of cells undergoing DNA synthesis and in the S-phase increased and the proportion of cells in the G0/G1 phase decreased in the group treated with high-doses of dipsacus saponins, promoting cell viability in this manner. 

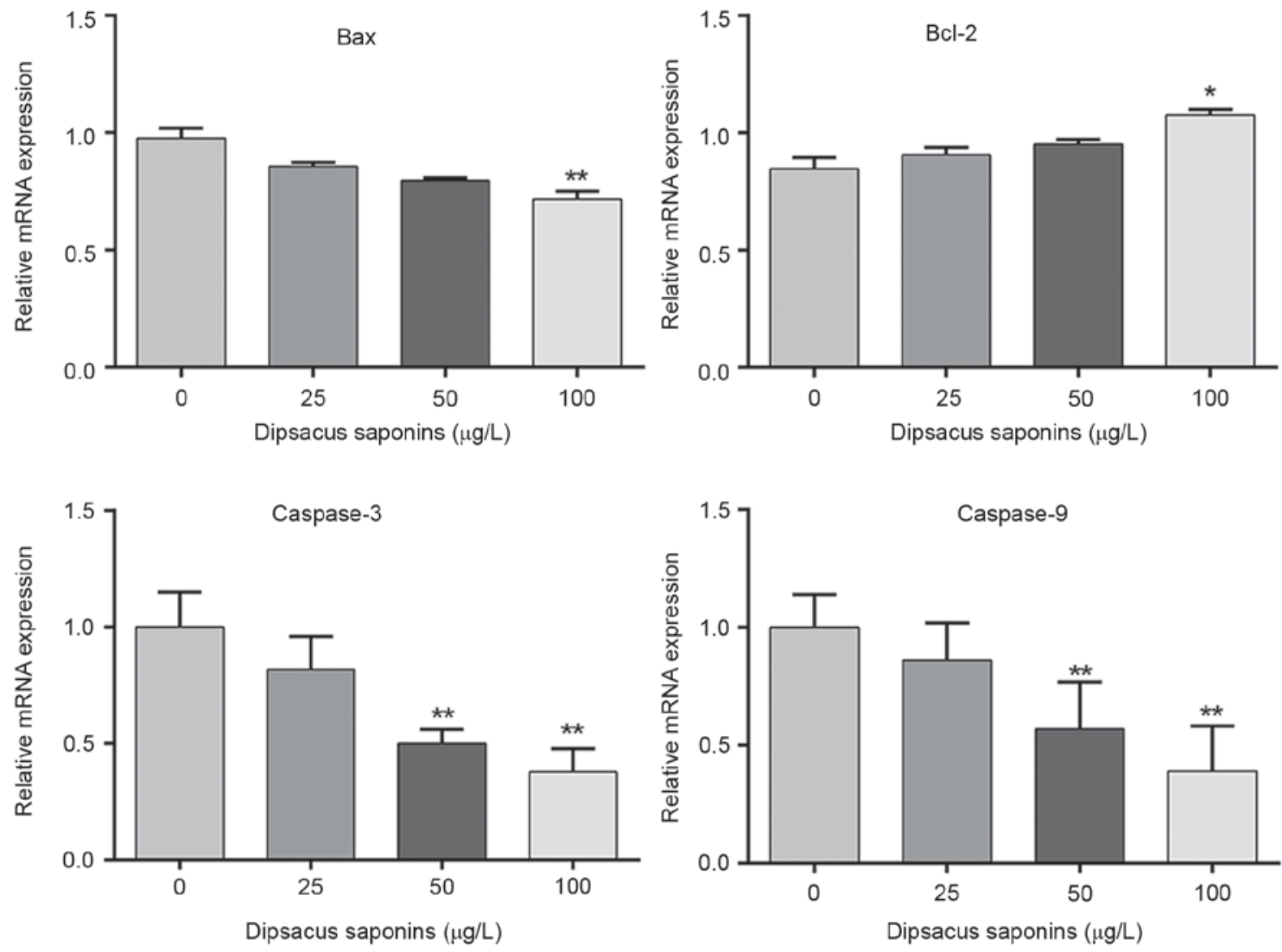

Figure 4. Expression of Bax, Bcl-2, caspase-3 and caspase-9 in the different groups. Levels of Bax, caspase-3 and caspase-9 mRNA decreased following treatment with dipsacus saponins in a concentration-dependent manner, while levels of Bcl-2 mRNA significantly increased in chondrocytes treated with $100 \mu \mathrm{g} / 1$ dipsacus saponins. ${ }^{*} \mathrm{P}<0.05,{ }^{* *} \mathrm{P}<0.01$ vs. $0 \mu \mathrm{g} / \mathrm{l}$.

The cell cycle is regulated by numerous factors: Cyclin A2 controls both $\mathrm{S}$ phase and G2/M transition (21), Cyclin E regulates the G1-S-phase transition (22) and Cyclin B is synthesized in late $\mathrm{S}$ and $\mathrm{G} 2$ phases and plays an important role in $\mathrm{G} 2-\mathrm{M}$ phase transition (23). Cyclin D1 is an important regulatory protein in the cell cycle that promotes changes in the cell cycle by regulating receptors, including the estrogen receptor and Sp1 (24). By contrast, p21 inhibits the growth of cells and determines whether the cell divides or undergoes apoptosis $(25,26)$. The present study demonstrated that levels of cyclin $\mathrm{Dl}$ and CDK4 expression significantly increased in chondrocytes treated with 50 and $100 \mu \mathrm{g} / 1$ dipsacus saponins in a concentration-dependent manner, whereas levels of p21 expression significantly decreased in groups treated with 50 and $100 \mu \mathrm{g} / 1$ dipsacus saponins and this decrease also occurred in a concentration-dependent manner. These results suggest that dipsacus saponins have a selective intervention role on chondrocytes and may effectively promote the viability of chondrocytes by regulating the cell cycle.

The regulation of cell apoptosis is an important factor in the maintenance of cells and cell apoptosis serves an important role in the regulation of the cellular pathology process (27-29). Proteins belonging to the Bcl-2 family have important regulatory effects on cell apoptosis and their abnormal expression is closely associated with the occurrence and development of many cancer types, including lung cancer (30). The present study determined that levels of Bcl-2 expression increased in the group treated with $100 \mu \mathrm{g} / \mathrm{l}$ dipsacus saponins. Bax belongs to the Bcl-2 family and has an inhibitory effect on Bcl-2. Additionally, it has been determined that the ratio of $\mathrm{Bax} / \mathrm{Bcl}-2$ is a key factor in determining the inhibition of apoptosis (31). Thus, Bax is one of the most important genes in the promotion of apoptosis. The present study demonstrated that levels of Bax expression significantly decreased following treatment with dipsacus saponins in concentration-dependent manner. SNP, which is an in vitro nitric oxide donor, promotes the initiation of apoptosis (32). The present study demonstrated that dipsacus saponins may inhibit the apoptosis induced by SNP and that the expression of caspases-3 and -9 decreased following treatment with dipsacus saponins in a concentration-dependent manner. Therefore, dipsacus saponins may inhibit the apoptosis of chondrocytes and preserve the function of chondrocytes.

In conclusion, dipsacus saponins may inhibit apoptosis signal transduction by up-regulating $\mathrm{Bcl}-2$ and down-regulating caspase- 9 , caspase- 3 and Bax expression. This means that dipsacus saponins may be used to effectively inhibit the apoptosis of chondrocytes, maintain the function of chondrocytes and suppress the loss of bone mass. Therefore, it may have therapeutic potential for osteoarthritis.

\section{References}

1. Nelson AE, Smith MW, Golightly YM and Jordan JM: 'Generalized osteoarthritis': A systematic review. Semin Arthritis Rheum 43: 713-720, 2014.

2. Laulan J, Marteau E and Bacle G: Wrist osteoarthritis. Orthop Traumatol Surg Res 101 (1 Suppl): S1-S9, 2015. 
3. Vos T, Flaxman AD, Naghavi M, Lozano R, Michaud C, Ezzati M, Shibuya K, Salomon JA, Abdalla S, Aboyans V, et al: Years lived with disability (YLDs) for 1160 sequelae of 289 diseases and injuries 1990-2010: A systematic analysis for the Global Burden of Disease Study 2010. Lancet 380: 2163-2196, 2012.

4. Mody GM and Brooks PM: Improving musculoskeletal health: Global issues. Best Pract Res Clin Rheumatol 26: 237-249, 2012.

5. Grotle M, Hagen KB, Natvig B, Dahl FA and Kvien TK Prevalence and burden of osteoarthritis: Results from a population survey in Norway. J Rheumatol 35: 677-684, 2008.

6. Rahman MM, Kopec JA, Goldsmith $\mathrm{CH}$, Anis $\mathrm{AH}$ and Cibere $\mathrm{J}$ : Validation of administrative osteoarthritis diagnosis using a clinical and radiological population-based cohort. Int J Rheumatol 2016: 6475318, 2016.

7. Doherty M, Watt I and Dieppe P: Influence of primary generalised osteoarthritis on development of secondary osteoarthritis. Lancet 2: 8-11, 1983.

8. Kellgren JH and Lawrence JS: Radiological assessment of osteo-arthrosis. Ann Rheum Dis 16: 494-502, 1957.

9. Hayashi D, Roemer FW and Guermazi A: Osteoarthritis year 2011 in review: Imaging in OA-a radiologists' perspective. Osteoarthritis Cartilage 20: 207-214, 2012.

10. Egloff $C$, Hügle $T$ and Valderrabano V: Biomechanics and pathomechanisms of osteoarthritis. Swiss Med Wkly 142 w13583, 2012.

11. Yang S, Kim J, Ryu JH, Oh H, Chun CH, Kim BJ, Min BH and Chun JS: Hypoxia-inducible factor-2alpha is a catabolic regulator of osteoarthritic cartilage destruction. Nat Med 16: 687-693, 2010.

12. Mortarino M, Franceschi A, Mancianti F, Bazzocchi C, Genchi C and Bandi C: Quantitative PCR in the diagnosis of Leishmania. Parassitologia 46: 163-167, 2004 (In Italian).

13. Niu Y, Li Y, Huang H, Kong X, Zhang R, Liu L, Sun Y, Wang T and Mei Q: Asperosaponin VI, a saponin component from Dipsacus asper wall, induces osteoblast differentiation through bone morphogenetic protein-2/p38 and extracellular signal-regulated kinase 1/2 pathway. Phytother Res 25: 1700-1706, 2011.

14. Rogart JN, Barrach HJ and Chichester CO: Articular collagen degradation in the Hulth-Telhag model of osteoarthritis. Osteoarthritis Cartilage 7: 539-547, 1999.

15. Committee for the Update of the Guide for the Care and Use of Laboratory Animals: Guide for the Care and Use of Laboratory Animals. 8th edition. The national academies press, NW Washington DC, 2010.

16. Livak KJ and Schmittgen TD: Analysis of relative gene expression data using real-time quantitative PCR and the 2(-Delta Delta C (T)) method. Methods 25: 402-408, 2001.

17. Chen CG, Thuillier D, Chin EN and Alliston T: Chondrocyte-intrinsic Smad3 represses Runx2-inducible matrix metalloproteinase 13 expression to maintain articular cartilage and prevent osteoarthritis. Arthritis Rheum 64: 3278-3289, 2012

18. Mobasheri A, Kalamegam G, Musumeci G and Batt ME: Chondrocyte and mesenchymal stem cell-based therapies for cartilage repair in osteoarthritis and related orthopaedic conditions. Maturitas 78: 188-198, 2014.
19. Wu XF, Zhou ZH and Zou J: MicroRNA-181 inhibits proliferation and promotes apoptosis of chondrocytes in osteoarthritis by targeting PTEN. Biochem Cell Biol 95: 437-444, 2017.

20. Li X, Chen J, Liang W, Li H, Liu F, Weng X, Lin P, Chen W, Zheng $\mathrm{C}, \mathrm{Xu} \mathrm{H}$, et al: Bushen Zhuangjin Decoction promotes chondrocyte proliferation by stimulating cell cycle progression. Exp Ther Med 9: 839-844, 2015.

21. Li Y,Peng Land Seto E: Histone Deacetylase 10 Regulates the Cell Cycle G2/M Phase Transition via a Novel Let-7-HMGA2-Cyclin A2 Pathway. Mol Cell Biol 35: 3547-3565, 2015.

22. Schwartz GK and Shah MA: Targeting the cell cycle: A new approach to cancer therapy. J Clin Oncol 23: 9408-9421, 2005.

23. Gavet $\mathrm{O}$ and Pines J: Progressive activation of CyclinB1-Cdk1 coordinates entry to mitosis. Dev Cell 18: 533-543, 2010.

24. Musgrove EA, Caldon CE, Barraclough J, Stone A and Sutherland RL: Cyclin D as a therapeutic target in cancer. Nat Rev Cancer 11: 558-572, 2011.

25. Duman-Seheel M, Weng L, Xin S and Du W: Hedgehog regulates cell growth and proliferation by inducing cyclin D and cyclin $\mathrm{E}$. Nature 417: 299-304, 2002.

26. Biyja V, Pachemik J, Vondrácek J, Soucek K, Cajánek L, Horvath V, Holubcová Z, Dvorák P and Hampl A: Lineage specific composition of cyclin D-CDK4/CDK6-p27 complexes reveals distinct functions of CDK4, CDK6 and individual D-type cyclins in differentiating cells of embryonic origin. Cell Prolif 41: 875-893, 2008

27. Baici A, Lang A, Hörler D and Knöpfel M: Cathepsin B as a marker of the dedifferentiated chondroeytes phenotype. Ann Rheum Dis 47: 684-691, 1988.

28. Hou WS, Li Z, Büttner FH, Bartnik E and Brömme D: Cleavage site specificity of cathepsin $\mathrm{K}$ toward cartilage proteoglycans and protease complrx formation. Biol Chem 384: 891-897, 2003.

29. Fasshauer M, Klein J, Neumann S, Eszlinger M and Paschke R: Isoproterenol inhibits resistin gene expression through a $\mathrm{G}(\mathrm{S})$ protein-coupled pathway in 3T3-L1 adipocytes. FEBS Lett 500: 60-63, 2001.

30. Zhao XD, He YY, Gao J, Zhao C, Zhang LL, Tian JY and Chen HL: High expression of Bcl-2 protein predicts favorable outcome in non-small cell lung cancer: Evidence From A Systematic Review And Meta-Analysis. Asian Pac J Cancer Prev 15: 8861-8869, 2014.

31. Del Principe MI, Dal Bo M, Bittolo T, Buccisano F, Rossi FM, Zucchetto A, Rossi D, Bomben R, Maurillo L, Cefalo M, et al: Clinical significance of BAX/BCL-2 ratio in chronic lymphocytic leukemia. Haematologica 101: 77-85, 2016.

32. Chen Q, Mei X, Han G, Ling P, Guo B, Guo Y, Shao H, Wang G, Cui Z, Bai Y and Xu F: Xanthan gum protects rabbit articular chondrocytes against sodium nitroprusside-induced apoptosis in vitro. Carbohydr Polym 131: 363-369, 2015. 